\title{
Differences in Academic Achievement by Grade Span Configuration: A Multiyear Texas Investigation
}

\author{
M. Chad Jones ${ }^{1}$, John R. Slate ${ }^{2}$, Cynthia Martinez-Garcia ${ }^{2}$, and George W. Moore ${ }^{2}$ \\ ${ }^{1}$ Iola Independent School District \\ ${ }^{2}$ Department of Educational Leadership, Sam Houston State University, Huntsville, TX USA \\ Email: profslate@aol.com
}

\begin{abstract}
In this empirical statewide investigation, the degree to which grade span configuration was related to the academic achievement of boys and girls in Texas public schools was addressed. Specifically analyzed were two grade span configurations (i.e., Pre-K/K-Grade 6/7/8 and Grades 6/7Grade 12) and the reading and mathematics performance of Grade 6, 7, and 8 boys and girls for the 2009-2010 and 2010-2011 school years. Although statistically significant differences were present in only two reading analyses, higher passing rates in reading were present in the elemiddle grade span configuration than in the secondary configuration in all 12 analyses. For the TAKS Mathematics passing rates, 11 of the 12 analyses revealed statistically significant differences, with small to moderate effect sizes.
\end{abstract}

Keywords: Grade span configuration, passing rates, TAKS reading, TAKS mathematics, elemiddle configuration, secondary configuration

\section{Introduction}

Grade-span configuration refers to the number and range of grade levels within a school (Coladarci \& Hancock, 2002). Many different grade span configurations are in existence today in U.S. schools. According to Coladarci and Hancock (2002), the most common grade span configuration containing Grade 6 was the Pre/K-Grade 6 configuration, which comprised $41.5 \%$ of all schools containing Grade 6 . The second most common grade span configuration containing Grade 6 was the traditional middle school with Grades 6-8. The lack of consistency from one school district to another is demonstrated by the fact that the third most prevalent configuration in the United States, by percentage, was the "other" column.

When examining grade span configurations in the United States for schools containing Grade 8, the most common grade span configuration is the traditional middle school including Grades 6-8. Once again, the category labeled as "other" made up the third most common configuration. This Grade 6 through Grade 8 grade span configuration exists, despite the fact that students attending Pre/K-Grade 8 schools scored statistically significantly higher than their counterparts attending traditional middle schools with Grades 6-8 (Clark, Slate, Combs, \& Moore, 2013a; Combs et al., 2011).

The wide variation in grade span configurations can be traced back to early schools in America. According to Clark et al. (2013a), rural schools were primarily one-room schools containing all grade levels, whereas urban schools tended to be divided into primary and secondary schools. The majority of Pre/K-Grade 8 and K-Grade 8 schools are in rural settings; however, urban school districts have begun to shift away from traditional Grade 6-8 middle schools towards more Pre/K-Grade 8 or K-Grade 8 schools (Blair, 2007). The debate over the benefits of one grade span configuration over another grade span configuration has ensued for decades (Howley, 2002). Specific questions in this debate are (a) Which grade span configuration is the most cost effective?; (b) Which grade span configuration yields the best academic achievement?; and (c) Which grade span configuration best meets the social and emotional needs of middle level children? The diverse factors that determine the efficacy of a specific grade span configuration vary from one district to another. According to McEntire (2002), factors educational leaders must consider when deciding on grade configuration are (a) the cost and length of student travel; (b) a possible increase or decrease in parental involvement; (c) the influence of older students on younger students; (d) the building design; (e) the number of school transitions; and, (f) the 
opportunity for interaction between age groups.

Three consistencies have appeared in the literature regarding grade span configuration: (a) no single grade span configuration serves all purposes; (b) no agreed upon best model exists; and (c) current practice is in a state of flux (Seller, 2005). The more research conducted on which specific grade span configuration is best for student achievement, cost efficiency, and meeting students' social and emotional needs, the better informed educational leaders are when making these decisions. Data from future research on grade span configuration may also be used by legislators to make policy decisions about grade span configuration.

\subsection{Purpose}

The purpose of this empirical investigation was to examine the extent to which the academic achievement of Grade 6, 7, and 8 boys and girls differed as a function of grade span configuration. A second purpose was to determine whether a trend was present for the academic performance of boys and girls by grade span configuration across the two years of data analyzed herein. The specific grade span configurations of interest in this investigation were elemiddle settings (i.e., Pre-K/K-Grade 6/7/8) and secondary settings (i.e., Grades 6/7-Grade 12). In this investigation, the grade span configuration for Grade 6, 7, and 8 students in elementary settings was referred to as elemiddle schools (Hough, 2005) and the grade span configuration for Grade 6, 7, and 8 students in secondary settings was referred to as secondary schools.

\section{$2 \quad$ Background}

Students often face discontinuity, alienation from peers, and insecurity when they experience the transition from an elementary school campus to a middle school or secondary school campus (Ashton, 2008). Many researchers (e.g., Becker, 1987; Byrnes \& Ruby, 2007; Clark, 2012; Clark et al., 2013a; Clark et al., 2013b; Schafer, 2010; Tucker \& Andrada, 1997; Wihry, Coladarci, \& Meadow, 1992) have demonstrated the presence of statistically significant relationships between grade span configuration and academic achievement. In these studies, students enrolled in K-8 elementary school settings demonstrated better academic performance than students enrolled in Grade 6-8 traditional middle school settings. Very few research studies are available, however, in which the academic performance of middle level students enrolled in elementary schools (i.e., Grades P/K-8) have been compared to the academic performance of students enrolled in secondary settings (i.e., Grades 6/7-12). Hough (2005) coined the term elemiddle schools to describe these P/K-Grade 8 schools. As such, data are needed by educational leaders, policymakers, and legislators as they make decisions or set policies regarding school grade span configuration.

As educational leaders make decisions about how to configure the schools within their district, one major factor they must take into account is the effect of school transitions on students and the timing of such transitions. Adolescents experience cognitive, physiological, social, and emotional developmental changes associated with puberty (Cullen \& Robles-Pina, 2012). When students transition from an elementary school campus to a middle or secondary school campus, issues associated with puberty become intertwined with similar issues related to the transition from elementary to secondary school (Aikins, Bierman, \& Parker, 2005). This period of transition for students is considered to be at a very critical time (Coffey, 2013).

School transitions often involve critical shifts in roles and settings (French, Seidman, Allen, \& Aber, 2000). The transition from an elementary school campus to a middle or secondary school campus involves physical, structural and contextual changes. Students enter a new building; they have a different structure for their school day; they are introduced to new peers; they experience more independence; and they experience less of a one-on-one student-teacher relationship (Cullen \& RoblesPina, 2012).

\subsection{Significance of the Study}

As student enrollment increases and new schools are built, educational leaders have to determine which 
configuration would provide the best results for their students. The optimal grade span configuration for students in Grades 6, 7, and 8 is still unknown. Given the inconsistency of grade span configurations from school district to school district, continually low student achievement scores, the inability to close the achievement gap, and ever changing accountability standards, educational leaders may be able to use results from empirical investigations to help them make informed decisions about grade span configuration.

Grade span configuration has been documented to influence student achievement (Clark et al., 2013a; Clark et al., 2013b). Previous researchers (e.g., Clark et al., 2013a; Clark et al., 2013b) have focused on comparing K-8 settings with 6-8 settings, as opposed to this study in which the emphasis was placed comparing K-8 settings with 6-12 settings. Decisions have to be made about campus grade configurations with the understanding that the more campuses present in a school district, the more transitions their students must experience. Therefore, an understanding of how transitions affect students of various ages is important in helping make these decisions. Given the fact that many different grade span configurations exist and their relationship to student academic achievement is not clearly documented, the need for more research on grade span configuration and academic achievement is pressing (Clark et al., 2013a; Clark et al., 2013b).

\section{$2.2 \quad$ Research Questions}

In this study, the following research questions were addressed: (a) What is the difference in the academic achievement (i.e., reading and mathematics) of Grade 6, 7, and 8 boys as a function of grade span configuration (i.e., elemiddle versus secondary) in the state of Texas?; and (b) What is the difference in the academic achievement (i.e., reading and mathematics) of Grade 6, 7, and 8 girls as a function of grade span configuration (i.e., elemiddle versus secondary) in the state of Texas? These two research questions were repeated separately for boys and for girls for each of the two school years of data (i.e., 2009-2010 and 2010-2011). As such, the extent to which trends might be present in grade span configuration and the academic achievement of boys and girls were examined.

\section{Method}

\subsection{Participants and Instrumentation}

Data from all Texas elemiddle and secondary schools containing students enrolled in a Grade 6, 7, and 8 classroom setting were obtained for the 2009-2010 and 2010-2011 school years. Data from nontraditional school settings such as charter schools or alternative education placement schools were not analyzed in this investigation. The grade span configuration, student demographic characteristics, and campus passing rates on the TAKS Reading and Mathematics tests were downloaded from the Texas Education Agency Academic Excellence Indicator System. As such, statistical analyses were conducted on data obtained from all Texas schools consisting of one of the two grade span configurations.

The Texas Education Agency makes publicly available aggregated passing rate data on the TAKS Reading and Mathematics tests, along with the grade span configuration of each campus. Along with these data, student demographic characteristics were requested. The archival data were provided by the Texas Education Agency Academic Excellence Indicator System database for the last two years in which the TAKS tests were administered (i.e., 2009-2010 and 2010-2011). Readers are referred to the Texas Education Agency website for detailed information regarding the psychometric qualities of the TAKS tests.

\subsection{Research Design}

This study was a causal-comparative, quantitative study (Creswell, 2009) in which archival data were obtained and analyzed. In such an ex post facto design, variables cannot be manipulated because they have already occurred. According to Silva (2010), ex post facto research is often used as a substitute for true experimentation to test hypotheses about cause and effect relationships because the data cannot be manipulated by the researcher. In this investigation, students had already taken the academic 
achievement measures from which test passing rates were analyzed. Furthermore, Grade 6, 7, and 8 students were already enrolled in either an elemiddle setting or a secondary setting.

\section{$4 \quad$ Results}

Prior to conducting inferential statistics to determine whether differences were present in the academic achievement of Grade 6, 7, and 8 boys and girls between elemiddle school settings and secondary school settings, checks were conducted to determine the extent to which these data were normally distributed (Onwuegbuzie \& Daniel, 2002). Although some of the data were not normally distributed, a decision was made to use parametric independent samples $t$-tests to answer the research questions. For results that were statistically significant at the .05 level, the effect size (i.e., Cohen's $d$ ) was calculated. Statistical results will now be presented by academic subject area separately for boys and for girls.

For the 2009-2010 school year for Grade 6 boys, the parametric independent samples $t$-test did not reveal a statistically significant difference, $t(32.44)=1.07, p=.29$, in the TAKS Reading passing rates between elemiddle schools and secondary schools. Grade 6 boys in both the elemiddle and secondary schools had similar passing rates on the TAKS Reading test. Readers are directed to Table 1 for the descriptive statistics for this analysis.

Table 1. Descriptive statistics for the TAKS reading passing rates by grade span configuration for grade 6,7 , and 8 boys for the 2009-2010 school year

\begin{tabular}{l|l|l|l}
\hline Grade Level and Grade Span Configuration & $n$ of school & $M$ & $S D$ \\
\hline Grade 6 & & & \\
\hline Elemiddle & 425 & 85.20 & 10.47 \\
\hline Secondary & 30 & 82.87 & 11.60 \\
\hline Grade 7 & & & \\
\hline Elemiddle & 44 & 84.32 & 10.15 \\
\hline Secondary & 92 & 81.02 & 13.22 \\
\hline Grade 8 & & & \\
\hline Elemiddle & 31 & 88.19 & 6.25 \\
\hline Secondary & 77 & 85.30 & 10.55 \\
\hline
\end{tabular}

Concerning the 2010-2011 school year for Grade 6 boys, the parametric independent samples $t$-test yielded a statistically significant difference, $t(26.76)=3.13, p=.004$, in the TAKS Reading test passing rates as a function of grade span configuration. This difference represented a small effect size (Cohen's $d$ ) of 0.44 (Cohen, 1988). Grade 6 boys who were enrolled in elemiddle schools had an average passing rate on the TAKS Reading exam that was $2.33 \%$ higher than the average passing rate of Grade 6 boys who were enrolled in secondary schools. The descriptive statistics for this analysis are presented in Table 2.

Table 2. Descriptive statistics for the TAKS reading passing rates by grade span configuration for grade 6,7 , and 8 boys for the 2010-2011 school year

\begin{tabular}{l|l|l|l}
\hline Grade Level and Grade Span Configuration & $n$ of schools & $M$ & $S D$ \\
\hline Grade 6 & & & \\
\hline Elemiddle & 467 & 84.41 & 10.00 \\
\hline Secondary & 25 & 78.12 & 9.77 \\
\hline Grade 7 & & & \\
\hline Elemiddle & 42 & 84.74 & 7.91 \\
\hline Secondary & 91 & 81.68 & 12.86 \\
\hline Grade 8 & & & \\
\hline Elemiddle & 40 & 85.85 & 8.59 \\
\hline Secondary & 92 & 85.32 & 14.66 \\
\hline
\end{tabular}


With respect to the 2009-2010 school year for Grade 7 boys, the parametric independent samples $t$ test did not reveal a statistically significant difference, $t(107.59)=1.60, p=.11$, in the TAKS Reading test passing rates as a function of grade span configuration. Grade 7 boys in both the elemiddle and secondary school settings had similar passing rates on the TAKS Reading test. The descriptive statistics for this analysis are presented in Table 1. Regarding the 2010-2011 school year for Grade 7 boys, the parametric independent samples $t$-test did not reveal a statistically significant difference, $t(120.36)=$ $1.68, p=.10$, in the TAKS Reading passing rates as a function of grade span configuration. Grade 7 boys in both the elemiddle and secondary school settings had similar passing rates on the TAKS Reading test. Table 2 contains the descriptive statistics for this school year. Concerning the 2009-2010 school year for Grade 8 boys, a statistically significant difference was not revealed at the conventional level, $t(91.06)=1.76, p=.08$, in the TAKS Reading test passing rates as a function of grade span configuration. Grade 8 boys in both the elemiddle and secondary school settings had similar passing rates on the TAKS Reading test. Descriptive statistics for this school year are presented in Table 1.

With respect to the 2010-2011 school year for Grade 8 boys, a statistically significant difference was present, $t(118.68)=2.70, p=.01$, between elemiddle schools and secondary schools on the TAKS Reading test passing rates. This difference represented a small effect size (Cohen's $d$ ) of 0.46 (Cohen, 1988). Grade 8 boys who were enrolled in elemiddle schools had an average passing rate on the TAKS Reading exam that was $2.89 \%$ higher than the average passing rate of Grade 8 boys who were enrolled in secondary schools. Delineated in Table 2 are the descriptive statistics for this analysis. For the 20092010 school year for Grade 6 girls, a statistically significant difference was not yielded, $t(30.99)=0.26, p$ $=.80$, between elemiddle schools and secondary schools on the TAKS Reading test passing rates. Grade 6 girls in both the elemiddle and secondary schools had similar passing rates on the TAKS Reading test. Readers are directed to Table 3 for the descriptive statistics for this analysis.

Table 3. Descriptive statistics for the TAKS reading passing rates by grade span configuration for grade 6 , 7, and 8 girls for the 2009-2010 school year

\begin{tabular}{l|l|l|l}
\hline Grade Level and Grade Span Configuration & $n$ of schools & $M$ & $S D$ \\
\hline Grade 6 & & & \\
\hline Elemiddle & 382 & 88.44 & 8.70 \\
\hline Secondary & 26 & 88.08 & 6.73 \\
\hline Grade 7 & & & \\
\hline Elemiddle & 38 & 86.39 & 9.34 \\
\hline Secondary & 88 & 85.09 & 9.88 \\
\hline Grade 8 & & & \\
\hline Elemiddle & 23 & 89.91 & 8.50 \\
\hline Secondary & 65 & 87.08 & 8.21 \\
\hline
\end{tabular}

Table 4. Descriptive statistics for the TAKS reading passing rates by grade span configuration for grade 6,7 , and 8 girls for the 2010-2011 school year

\begin{tabular}{l|l|l|l}
\hline Grade Level and Grade Span Configuration & $n$ of schools & $M$ & $S D$ \\
\hline Grade 6 & & & \\
\hline Elemiddle & 426 & 87.87 & 7.79 \\
\hline Secondary & 25 & 85.04 & 8.81 \\
\hline Grade 7 & & & \\
\hline Elemiddle & 36 & 85.86 & 9.49 \\
\hline Secondary & 86 & 85.88 & 9.36 \\
\hline Grade 8 & & & \\
\hline Elemiddle & 25 & 89.68 & 8.90 \\
\hline Secondary & 71 & 86.11 & 8.23 \\
\hline
\end{tabular}


Regarding the 2010-2011 school year for Grade 6 girls, a statistically significant difference was not revealed, $t(26.54)=1.57, p=.13$, in passing rates on the TAKS Reading test as a function of grade span configuration. Grade 6 girls in both the elemiddle and secondary school settings had similar passing rates on the TAKS Reading test. Descriptive statistics for this school year are presented in Table 4.

Concerning the 2009-2010 school year for Grade 7 girls, a statistically significant difference was not present, $t(74.08)=0.71, p=.48$, in passing rates on the TAKS Reading test as a function of grade span configuration. Grade 7 girls in both the elemiddle and secondary school settings had similar passing rates on the TAKS Reading test. Delineated in Table 3 are the descriptive statistics for this school year. With respect to the 2010-2011 school year for Grade 7 girls, a statistically significant difference was not yielded, $t(64.91)=-0.01, p=.99$, in passing rates on the TAKS Reading test as a function of grade span configuration. Grade 7 girls in both the elemiddle and secondary school settings had commensurate passing rates on the TAKS Reading test. Descriptive statistics for this school year are presented in Table 4.

Regarding the 2009-2010 school year for Grade 8 girls, a statistically significant difference was not revealed, $t(37.51)=1.39, p=.17$, in passing rates on the TAKS Reading test as a function of grade span configuration. Grade 8 girls in both the elemiddle and secondary school settings had similar passing rates on the TAKS Reading test. Table 3 contains the descriptive statistics for this school year. Concerning the 2010-2011 school year for Grade 8 girls, a statistically significant difference was not present, $t(39.09)=1.74, p=.09$, in passing rates on the TAKS Reading test as a function of grade span configuration. Grade 8 girls in both the elemiddle and secondary school settings had commensurate passing rates on the TAKS Reading test. Descriptive statistics for this school year are presented in Table 4

With respect to the 2009-2010 school year for Grade 6 boys, a statistically significant difference was present, $t(30.78)=3.45, p=.01$, on the TAKS Mathematics test passing rates as a function of grade span configuration. This difference represented a moderate effect size (Cohen's $d$ ) of 0.70 (Cohen, 1988). Grade 6 boys who were enrolled in elemiddle schools had an average passing rate on the TAKS Mathematics exam that was $9.22 \%$ higher than the average passing rate of Grade 6 boys who were enrolled in secondary schools. Delineated in Table 5 are the descriptive statistics for this analysis.

Table 5. Descriptive statistics for the TAKS mathematics passing rates by grade span configuration for grade 6,7 , and 8 boys for the 2009-2010 school year

\begin{tabular}{l|l|l|l}
\hline Grade Level and Grade Span Configuration & $n$ of schools & $M$ & $S D$ \\
\hline Grade 6 & & & \\
\hline Elemiddle & 441 & 84.29 & 12.10 \\
\hline Secondary & 29 & 75.07 & 14.04 \\
\hline Grade 7 & & & \\
\hline Elemiddle & 45 & 78.73 & 13.41 \\
\hline Secondary & 104 & 75.54 & 18.11 \\
\hline Grade 8 & & & \\
\hline Elemiddle & 44 & 82.23 & 15.52 \\
\hline Secondary & 105 & 74.55 & 16.39 \\
\hline
\end{tabular}

Regarding the 2010-2011 school year for Grade 6 boys, a statistically significant difference was revealed, $t(30.31)=2.79, p=.01$, on the TAKS Mathematics test passing rates as a function of grade span configuration. This difference represented a moderate effect size (Cohen's $d$ ) of 0.58 (Cohen, 1988). Similar to the previous year, Grade 6 boys who were enrolled in elemiddle schools had an average passing rate on the TAKS Reading exam that was $2.68 \%$ higher than the average passing rate of Grade 6 boys who were enrolled in secondary schools. Revealed in Table 6 are the descriptive statistics for this analysis. 
Table 6. Descriptive statistics for the TAKS mathematics passing rates by grade span configuration for grade 6,7 , and 8 boys for the 2010-2011 school year

\begin{tabular}{l|l|l|l}
\hline Grade Level and Grade Span Configuration & $n$ of schools & $M$ & $S D$ \\
\hline Grade 6 & & & \\
\hline Elemiddle & 453 & 84.18 & 11.27 \\
\hline Secondary & 29 & 76.69 & 14.16 \\
\hline Grade 7 & & & \\
\hline Elemiddle & 51 & 81.31 & 10.67 \\
\hline Secondary & 102 & 75.76 & 13.18 \\
\hline Grade 8 & & & \\
\hline Elemiddle & 46 & 80.24 & 13.38 \\
\hline Secondary & 109 & 72.19 & 18.30 \\
\hline
\end{tabular}

Concerning the 2009-2010 school year for Grade 7 boys, a statistically significant difference was not present, $t(111.27)=1.19, p=.23$, in passing rates on the TAKS Mathematics test as a function of grade span configuration. Grade 7 boys in both the elemiddle and secondary school settings had commensurate passing rates on the TAKS Mathematics test. Descriptive statistics for this school year are presented in Table 5. With respect to the 2010-2011 school year for Grade 7 boys, a statistically significant difference was yielded, $t(120.64)=2.80, p=.01$, on the TAKS Mathematics test passing rates as a function of grade span configuration. This difference represented a small effect size (Cohen's $d$ ) of 0.47 (Cohen, 1988). Grade 7 boys who were enrolled in elemiddle schools had an average passing rate on the TAKS Mathematics exam that was $5.55 \%$ higher than the average passing rate of Grade 7 boys who were enrolled in secondary schools. Delineated in Table 6 are the descriptive statistics for this analysis. Regarding the 2009-2010 school year for Grade 8 boys, a statistically significant difference was revealed, $t(113.19)=3.25, p=.01$, on the TAKS Mathematics test passing rates of as a function of grade span configuration. This difference represented a moderate effect size (Cohen's $d$ ) of 0.55 (Cohen, 1988). Grade 8 boys who were enrolled in elemiddle schools had an average passing rate on the TAKS Mathematics exam that was $7.68 \%$ higher than the average passing rate of Grade 8 boys who were enrolled in secondary schools. The descriptive statistics for this analysis are presented in Table 5.

Concerning the 2010-2011 school year for Grade 8 boys, a statistically significant difference was yielded, $t(114.36)=3.05, p=.01$, on the TAKS Mathematics passing rates as a function of grade span configuration. This difference represented a moderate effect size (Cohen's $d$ ) of 0.50 (Cohen, 1988). Grade 8 boys who were enrolled in elemiddle schools had an average passing rate on the TAKS Mathematics exam that was $8.05 \%$ higher than the average passing rate of Grade 8 boys who were enrolled in secondary schools. Readers are directed to Table 6 for the descriptive statistics for this school year.

Table 7. Descriptive statistics for the TAKS mathematics passing rates by grade span configuration for grade 6,7 , and 8 girls for the 2009-2010 school year

\begin{tabular}{l|l|l|l}
\hline Grade Level and Grade Span Configuration & $n$ of schools & $M$ & $S D$ \\
\hline Grade 6 & & & \\
\hline Elemiddle & 421 & 83.73 & 12.34 \\
\hline Secondary & 30 & 76.63 & 18.17 \\
\hline Grade 7 & & & \\
\hline Elemiddle & 42 & 80.98 & 12.21 \\
\hline Secondary & 100 & 74.50 & 15.64 \\
\hline Grade 8 & & & \\
\hline Elemiddle & 35 & 79.11 & 13.52 \\
\hline Secondary & 96 & 73.19 & 17.54 \\
\hline
\end{tabular}


With respect to the 2009-2010 school year for Grade 6 girls, a statistically significant difference was present, $t(30.93)=2.12, p=.04$, on the TAKS Mathematics test passing rates as a function of grade span configuration. This difference represented a small effect size (Cohen's d) of 0.46 (Cohen, 1988). Grade 6 girls who were enrolled in elemiddle schools had an average passing rate on the TAKS Mathematics exam that was $7.10 \%$ higher than the average passing rate of Grade 6 girls who were enrolled in secondary schools. Delineated in Table 7 are the descriptive statistics for this analysis.

Regarding the 2010-2011 school year for Grade 6 girls, a statistically significant difference was revealed, $t(27.96)=2.29, p=.03$, on the TAKS Mathematics test passing rates as a function of grade span configuration. This difference represented a moderate effect size (Cohen's $d$ ) of 0.50 (Cohen, 1988). Grade 6 girls who were enrolled in elemiddle schools had an average passing rate on the TAKS Mathematics exam that was 5.99\% higher than the average passing rate of Grade 6 girls who were enrolled in secondary schools. The descriptive statistics for this analysis are presented in Table 8.

Table 8. Descriptive statistics for the TAKS mathematics passing rates by grade span configuration for grade 6,7 , and 8 girls for the 2010-2011 school year

\begin{tabular}{l|l|l|l}
\hline Grade Level and Grade Span Configuration & $n$ of schools & $M$ & $S D$ \\
\hline Grade 6 & & & \\
\hline Elemiddle & 442 & 85.36 & 10.42 \\
\hline Secondary & 27 & 79.37 & 13.37 \\
\hline Grade 7 & & & \\
\hline Elemiddle & 46 & 82.20 & 14.30 \\
\hline Secondary & 104 & 77.32 & 14.54 \\
\hline Grade 8 & & & \\
\hline Elemiddle & 36 & 81.92 & 13.93 \\
\hline Secondary & 110 & 74.93 & 15.09 \\
\hline
\end{tabular}

Concerning the 2009-2010 school year for Grade 7 girls, a statistically significant difference was present, $t(97.73)=2.65, p=.01$, on the TAKS Mathematics test passing rates as a function of grade span configuration. This difference represented a small effect size (Cohen's d) of 0.46 (Cohen, 1988). Grade 7 girls who were enrolled in elemiddle schools had an average passing rate on the TAKS Mathematics exam that was $6.48 \%$ higher than the average passing rate of Grade 7 girls who were enrolled in secondary schools. Presented in Table 7 are the descriptive statistics for this school year. With respect to the 2010-2011 school year for Grade 7 girls, a statistically significant difference was yielded, $t(87.56)=1.12, p=.05$, on the TAKS Mathematics test passing rates as a function of grade span configuration. This difference represented a small effect size (Cohen's $d$ ) of 0.34 (Cohen, 1988). Grade 7 girls who were enrolled in elemiddle schools had an average passing rate on the TAKS Mathematics exam that was $4.88 \%$ higher than the average passing rate of Grade 7 girls who were enrolled in secondary schools. Table 8 contains the descriptive statistics for this analysis.

Regarding the 2009-2010 school year for Grade 8 girls, a statistically significant difference was revealed, $t(78.02)=2.04, p=.05$, on the TAKS Mathematics test passing rates as a function of grade span configuration. This difference represented a small effect size (Cohen's d) of 0.38 (Cohen, 1988). Grade 8 girls who were enrolled in elemiddle schools had an average passing rate on the TAKS Mathematics exam that was $5.93 \%$ higher than the average passing rate of Grade 8 girls who were enrolled in secondary schools. The descriptive statistics for this analysis are presented in Table 7. Concerning the 2010-2011 school year for Grade 8 girls, a statistically significant difference was yielded, $t(64.02)=2.56, p=.01$, on the TAKS Mathematics test passing rates as a function of grade span configuration. This difference represented a small effect size (Cohen's $d$ ) of 0.48 (Cohen, 1988). Grade 8 girls who were enrolled in elemiddle schools had an average passing rate on the TAKS Mathematics exam that was $6.99 \%$ higher than the average passing rate of Grade 8 girls who were enrolled in secondary schools. Table 8 contains the descriptive statistics for this school year. 


\section{Discussion}

In this multiyear statewide analysis, the degree to which grade span configuration was related to the reading and mathematics achievement of Grade 6, 7, and 8 boys and girls in Texas public schools was addressed. With respect to the TAKS Reading passing rates, two statistically significant differences, with small effect sizes, were present. Although the other TAKS Reading analyses were not statistically significant, readers should note that passing rates on the TAKS Reading tests were higher at the elemiddle schools than in secondary schools in all 12 analyses.

Concerning the TAKS Mathematics passing rate analyses, statistically significant differences were revealed in 11 of the 12 analyses. Small to moderate effect sizes were present. In all of the analyses, passing rates on the TAKS Mathematics test were higher at the elemiddle grade span configurations than for the secondary grade span configurations. Regression in student achievement has been documented to occur during the transition from elementary school to middle school (Alspaugh, 1998; Alspaugh \& Harting, 1995). Many researchers (e.g., Becker, 1987; Byrnes \& Ruby, 2007; Clark, 2012; Clark et al., 2013a; Clark et al., 2013b; Franklin \& Glasscock, 1996; Schafer, 2010; Tucker \& Andrada, 1997; Wihry et al., 1992) have demonstrated the presence of statistically significant relationships between grade span configuration and academic achievement. In these studies, middle level students enrolled in K-8 school settings demonstrated better academic performance than students enrolled in traditional middle school settings (i.e., Grades 6-8). Few research studies are available, however, in which the passing rates of middle level students enrolled in elementary schools (i.e., Grades Pre-K/KGrade $6,7,8$ ) have been compared to the passing rates of students enrolled in secondary settings (i.e., Grades 6/7-12).

\subsection{Implications for Policy and Practice}

Despite a vast variety of grade span configurations, the ideal grade span configuration for boys and girls in Grades 6, 7, and 8 is still unknown. Given continually low student achievement scores, the inconsistencies of grade span configurations from school district to school district, ever changing accountability standards, and the inability to close the achievement gap, school administrators may be able to analyze data from studies such as this one to help them make decisions about grade span configuration. The data collected from this study may be analyzed by legislatures and school leaders to address some of these issues in education today.

Grade span configuration has been documented to influence student achievement (Clark et al., 2013a, 2013b). As enrollment increases and new schools are built, school administrators have to determine what configuration would provide the best results for their students. The problem is that school administrators must make decisions about campus grade configurations with the understanding that the more campuses they have, the more transitions their students must undergo. Therefore, an understanding of how transitions affect students of various ages is important in helping make these decisions. Given the fact that many different grade span configurations exist and student academic achievement is low, the need for more research on grade span configuration and academic achievement is needed (Clark et al., 2013a).

\subsection{Suggestions for Future Research}

Investigated in this study was the extent to which differences were present in the TAKS Reading and Mathematics passing rates between Grade 6, 7, and 8 boys and girls in Texas as a function of grade span configuration. Specifically examined were passing rates for Grade 6,7 , and 8 boys and girls who were either enrolled in elemiddle settings (i.e., Pre-K/K-Grade 6/7/8) or in secondary settings (i.e., Grades 6/7-Grade 12). In this investigation, data were analyzed at the aggregated campus level. Researchers are encouraged to analyze individual student level data rather than campus level passing rate data. Such investigations would permit a more detailed analysis of the relationship of grade span configuration to student performance.

Data from this investigation were composed solely of the TAKS Reading and Mathematics passing rates for the 2009-2010 and 2010-2011 school years. Data from the new State of Texas Assessment of Academic Readiness (STAAR) were not used in this study due to problems in its initial implementation 
as the replacement of TAKS. Data from the STAAR were not considered valid for this study due to the inconsistencies with state accountability from 2012-2015. In time, scores from the STAAR assessments will yield valid and valuable data from which researchers can determine whether grade span configuration is related to student achievement, as measured by the STAAR.

\section{Conclusion}

The purpose of this research study was to determine the degree to which differences were present in the TAKS Reading and Mathematics passing rates of Grade 6, 7, and 8 boys and girls in Texas as a function of grade span configuration. In reading, two out of the 12 analyses for boys revealed statistically significant differences. In 11 of the 12 instances, however, reading performance for boys was higher in the elemiddle settings than in secondary settings. Statistically significant differences were revealed in five of the six analyses of student mathematics passing rates for girls. In all six analyses, mathematics performance was better for girls in the elemiddle settings than in secondary settings. Consistent with previous research (Clark et al., 2013a), students in an elementary setting who undergo fewer transitions perform better on the TAKS Reading and Mathematics exam than those students who experience more transitions.

\section{References}

1. Aikins, J. W., Bierman, K. L., \& Parker, J. G. (2005). Navigating the transition to junior high school: The influence of pre-transition friendship and self-system characteristics. Social Development, 14, 42-60.

2. Alspaugh, J. W. (1998). Achievement loss associated with the transition to middle school and high school. Journal of Educational Research, 92(1), 20-25.

3. Alspaugh, J. W., \& Harting, R. D. (1995). Transition effects of school grade-level organization on student achievement. Journal of Research and Development in Education, 28, 145-149.

4. Ashton, R. (2008). Improving the transfer to secondary school: How every child's voice can matter. Support for Learning, 23, 176-182. doi:10.1111/j.1467-9604.2008.00391.x.

5. Becker, H. J. (1987). Addressing the needs of different groups of early adolescents: Effects of varying school and classroom organizational practices on students from different social backgrounds and abilities (Report No. 16). Baltimore, MD: The Johns Hopkins University Center for Research on Elementary and Middle Schools.

6. Blair, L. (2007). Back to the future: The shift to K-8 schools. SEDL Letter, 20(1), 1-10.

7. Byrnes, V., \& Ruby, A. (2007). Comparing achievement between K-8 and middle schools: A large-scale empirical study. American Journal of Education, 114, 101-135. doi:10.1086/520693.

8. Clark, D. M. (2012). A comparative analysis of grade span configurations and academic achievement among 6-8 and K-8 public schools in Texas. (Doctoral Dissertation). Retrieved from Proquest Dissertations and Theses. (UMI No. 3531779)

9. Clark, D. M., Slate, J. R., Combs, J. P., \& Moore, G. W. (2013a). 6-8 and K-8 Texas public schools: Differences in writing, science, and social studies. Frontiers in Education, 1(1), 1-5.

10.Clark, D. M., Slate, J. R., Combs, J. P., \& Moore, G. W. (2013b). Math and reading differences between 6-8 and K-8 grade span configurations: A multiyear, statewide analysis. Current Issues in Education, 16(2), 1-15. Retrieved from http://cie.asu.edu/ojs/index.php/cieatasu/article/view/1144.

11.Clark, D. M., Slate, J. R., Combs, J. P., \& Moore, G. W. (2014). A conceptual analysis of 6-8 and K-8 grade span configurations. The Online Journal of New Horizons in Education, 4(1), 1-24. Retrieved from http://www.tojned.net/volume.php?volume=4\&issue $=1$.

12.Cohen, J. (1988). Statistical power analysis for the behavioral sciences (2nd ed.). Hillsdale, NJ: Lawrence Erlbaum.

13.Coffey, A. (2013). Relationships: The key to successful transition from primary school to secondary school? Improving Schools, 16(3), 261-271.

14.Coladarci, T., \& Hancock, J. (2002). The (limited) evidence regarding effects of grade-span configurations on academic achievement: What rural educators should know. Journal of Research in Rural Education, 17(3), 189192. 
15.Combs, J. P., Clark, D. M., Moore, G. W., Onwuegbuzie, A. J., Edmonson, S. L., \& Slate, J. R. (2011). Academic achievement for fifth-grade students in elementary and intermediate school settings: Grade span configurations. Current Issues in Education, 14(1). Retrieved from http://cie.asu.edu/.

16.Creswell, J. W. (2009). Research design: Qualitative, quantitative, and mixed methods approaches (3rd ed.). Thousand Oaks, CA: Sage.

17.Cullen, M., \& Robles-Pina, R. (2012). Grade transitions from elementary school to secondary school: What is the impact on students? Southwest Teacher Education Journal, 2(1), 31-38.

18.Franklin, B. J., \& Glasscock, C. H. (1996, October). The relationship between grade configuration and student performance in rural schools. Paper presented at the Annual Conference of the National Rural Education Association, San Antonio, TX (ERIC Document Reproduction Service No. ED403083). Retrieved from http://www.eric.ed.gov/PDFS/ED403083.pdf.

19.French, S. E., Seidman E., Allen, L., \& Aber, L. J. (2000). Racial/ethnic identity, congruence with social context and the transition to high school. Journal of Adolescent Research, 15, 582-602.

20.Hough, D. L. (2005). The rise of the 'elemiddle' school. School Administrator, 62(3), 10-14.

21.Howley, C. B. (2002). Grade-span configurations. School Administrator, 59(3), 24-29.

22.McEntire, N. (2002). Grade configuration in K-12 schools. Clearinghouse on Early Education and Parenting, 1-18.

23. Onwuegbuzie, A. J., \& Daniel, L. G. (2002). Uses and misuses of the correlation coefficient. Research in the Schools, 9(1), 73-90.

24.Schafer, K. L. (2010). The impact of grade configuration on sixth grade academic achievement in Florida Public schools. Doctoral dissertation (UMI No. 3415047), University of Central Florida, FL.

25.Seller, W. (2005). Schools and school districts in educational reform examining the space in-between. Journal of Educational Change, 6(1), 1-5. doi:10.1007/s10833-004-7728-x.

26.Silva, C. N. (2010). Ex post facto study. Encyclopedia of research design. Thousand Oaks, CA: Sage. doi:10.4135/9781412961288.

27.Tucker, C. G., \& Andrada, G. N. (1997, March). Accountability works: Analysis of performance by grade span of school. Paper presented at the annual meeting of the American Educational Research Association, Chicago, IL.

28.Wihry, D. F., Coladarci, T., \& Meadow, C. (1992). Grade span and eighth-grade academic achievement: Evidence from a predominantly rural state. Journal of Research in Rural Education, 8(2), 58-70. 